\title{
Composição Química e Predição do Valor Nutritivo de Dietas para Eqüinos ${ }^{1}$ \\ Maria Izabel Vieira de Almeida ${ }^{2}$, Walter Motta Ferreira ${ }^{3}$, Fernando Queiroz de Almeida ${ }^{4}$, Lúcio Carlos Gonçalves ${ }^{3}$, Adalgisa Souza Carneiro Rezende ${ }^{3}$
}

\begin{abstract}
RESUMO - O objetivo deste trabalho foi reunir informações da literatura sobre a composição de dietas para eqüinos e estimar, por meio de equações de regressão, os conteúdos de energia e proteína digestível, a partir da composição química dietética destas dietas. Foi feito um estudo de correlação entre o conteúdo e os coeficientes de digestibilidade aparente dos nutrientes, nas dietas experimentais, selecionando-se as melhores correlações entre ED, CDE, CDMO e CDPB e os componentes químicos das dietas. Os valores de CDE, CDMO, CDPB e do teor de energia digestível foram submetidos à análise de regressão linear simples e múltipla, em função dos componentes químicos das dietas e de duas classes, dietas simples com alimentos volumosos e dietas mistas com alimentos volumosos e concentrados. As melhores equações de predição do conteúdo de ED, expressas em Mcal/kg MS, para dietas em geral foram: $\mathrm{ED}=-0,104+0,0416 \mathrm{CDMO}\left(\mathrm{r}^{2}=0,85\right)$, $\mathrm{ED}=5,0285-0,0144 \mathrm{MO}-0,0424 \mathrm{FDA}\left(\mathrm{R}^{2}=0,89\right)$ e $\mathrm{ED}=3,7868-0,044 \mathrm{FDA}\left(\mathrm{R}^{2}=0,87\right)$. Em dietas volumosas, a equação mais adequada foi: $\mathrm{ED}=0,2273+0,0352 \mathrm{CDMO}\left(\mathrm{r}^{2}=0,70\right)$ e em dietas mistas, $\mathrm{ED}=-0,3803+0,0459 \mathrm{CDMO}\left(\mathrm{r}^{2}=0,86\right)$. A equação de predição do coeficiente de digestibilidade da proteína bruta para alimentos volumosos, CDPB $(\%)=38,2446+1,7381 \mathrm{~PB}\left(\mathrm{r}^{2}=0,53\right)$, mostrou-se adequada para a estimativa do conteúdo em proteína digestível dos fenos de alfafa e capim coast-cross.
\end{abstract}

Palavras-chave: alimentos, energia digestível, equações de predição, proteína digestível

\section{Chemical Composition and Prediction of Nutritive Value of Diets for Horses}

\begin{abstract}
The objetive of this experiment was to obtain data from literature about diet composition for horses and to estimate the digestible energy and digestible protein contents by regression equations from chemical composition of these diets. Data were submitted to a correlation study among the content of nutrients in experimental diets and apparent digestibility coefficients, selecting the best correlation among DE, EAD, OMAD, CPAD and nutrients of diets. The values of EAD, OMAD and CPAD and digestible energy contents were fitted to simple and multiple linear regression equations in function of the nutrients contents fo the diets and in two classes of diets, roughage and mixed (roughage plus concentrate) diets. The best prediction equations for DE contents, in Mcal/kg DM, to all horses diets were: $\mathrm{ED}=-0.104+0.0416 \mathrm{OMAD}\left(\mathrm{r}^{2}=0.85\right), \mathrm{DE}=5.0285-0.0144 \mathrm{OM}-0.0424 \mathrm{ADF}\left(\mathrm{R}^{2}=0.89\right)$ and $\mathrm{DE}=3.7868-0.044 \mathrm{ADF}$ $\left(\mathrm{R}^{2}=0.87\right)$. The most appropriate equation in roughage diets was: $\mathrm{DE}=0.2273+0.0352$ OMAD $\left(\mathrm{r}^{2}=0,70\right)$ and in mixed diets was: $\mathrm{DE}=-0.3803+0.0459 \mathrm{OMAD}\left(\mathrm{r}^{2}=0,86\right)$. Prediction equation of apparent digestibility coefficient for crude protein in roughage diets was, $\mathrm{CPAD}(\%)=38.2446+1.7381 \mathrm{CP}\left(\mathrm{r}^{2}=0.53\right)$, appropriate to estimate the contents of digestible protein in alfalfa and coast-cross grass hays.
\end{abstract}

Key Words: feedstuffs, digestible energy, equation prediction, digestible protein

\section{Introdução}

Sabe-se que a digestão dos alimentos na espécie eqüina, desde que estes não sejam excessivos, independe da intensidade de trabalho e da temperatura ambiente. Por outro lado, a digestibilidade é influenciada pelas variações individuais, pela eficácia da mastigação, pela presença de parasitos internos, pelo tempo de permanência do alimento no trato digestivo, pela composição e pelo volume do alimento (WOLTER, 1975).

Os experimentos de digestibilidade in vivo são muito dispendiosos e exigem que os animais permaneçam longo período consumindo grandes quantida- des de alimentos, não sendo apropriados como metodologia rotineira, mas sim como testes de referência. Portanto, há interesse crescente no sentido de desenvolver modelos matemáticos para predição da digestibilidade dos alimentos, a partir de sua composição bromatológica conhecida (MELO, 1990).

É necessário conhecer a energia disponível dos alimentos para uso prático em cálculos de rações e na comparação do valor nutricional e econômico das dietas. Em muitos casos, faz-se necessário estimar a digestibilidade dos nutrientes, com base apenas na concentração de um ou mais componentes no alimento; para tal fim, é possível a utilização de equações de

\footnotetext{
1 Parte da Dissertação apresentada à Universidade Federal de Minas Gerais para obtenção do título de Magister Scientiae.

2 Zootecnista, Doutorando em Zootecnia. DZO - UFV - 36571-000 - Viçosa, MG. E.mail: miva@homenet.com.br

3 Professor do DZO - EV- UFMG - 30161-970 - Belo Horizonte, MG.

${ }^{4}$ Professor do DPA - IZ - UFRRJ - 23851-970 - Seropédica. RJ.
} 
regressão simples e múltiplas que relacionem a digestibilidade dos nutrientes de alimentos previamente avaliados em ensaios de digestão e a composição química dos alimentos testados (WEISS, 1993). Diferentes componentes das dietas de eqüinos têm sido usados para produzir equações de regressão, com o objetivo de predizer os coeficientes de digestibilidade da matéria seca, matéria orgânica, proteína bruta e energia e o teor de energia digestível (FONNESBECK, 1981).

Os métodos para estimar a energia devem ser rápidos, baratos e precisos, para que sejam adotados pelos laboratórios comerciais de testes de alimentos. O total de energia presente em um alimento, a energia bruta, pode ser quantificado por meio de uma bomba calorimétrica, no entanto, a variabilidade na digestibilidade e no metabolismo dos diferentes alimentos impede o uso da energia bruta para formulação de dietas ou a comparação de alimentos. As fontes de variação incluem fatores relacionados aos animais, aos alimentos e à forma de alimentação. De modo geral, a maioria dos laboratórios usa equações empíricas, com base nos teores de fibra em detergente ácido, para estimar o conteúdo de energia disponível nos alimentos (WEISS, 1998).

O teor de proteína bruta está positivamente correlacionado ( $\mathrm{r}=15$ a 90\%) com o conteúdo de energia digestível das forragens e negativamente correlacionado com o conteúdo de fibra nos alimentos (MINSON, 1982). Embora a proteína bruta represente uma fração uniforme do alimento, não é considerada como um preditor muito acurado da energia digestível em forragens, porém pode ser correlacionado com o conteúdo em proteína digestível em alimentos para eqüinos (NATIONAL RESEARCH COUNCIL - NRC, 1989).

Os métodos mais comumente utilizados para medir a relação entre uma variável dependente e uma independente são o coeficiente de correlação ( $r$ ) e o coeficiente de determinação $\left(\mathrm{r}^{2}\right.$ e $\left.\mathrm{R}^{2}\right), \mathrm{r}^{2}$ para regressões simples e $\mathrm{R}^{2}$ para regressões múltiplas. O coeficiente de determinação mede o quanto uma população de variáveis é bem representada por determinado modelo matemático. As equações de regressão são preditores mais precisos quando os valores das variáveis independentes estão próximos à média, do que quando se distanciam desta (MINSON, 1982).

O presente trabalho teve como objetivos reunir informações disponíveis na literatura sobre a composição de dietas ou alimentos utilizados na alimentação de eqüinos e as suas respectivas digestibilidades e estimar, por meio de equações de regressão, o conteúdo de energia digestível e proteína digestível em dietas, para eqüinos, a partir da composição bromatológica.

\section{Material e Métodos}

Foi feito um levantamento bibliográfico referente a trabalhos científicos que reportassem a dados de composição e digestibilidade aparente dos nutrientes das dietas em ensaios de digestão realizados com eqüinos. Nessa revisão bibliográfica, foram obtidos 383 dados dos ensaios de digestão, dos quais 143 representavam dietas simples com alimentos volumosos e 240, dietas mistas com alimentos volumosos e concentrados, que foram reunidos em um banco de dados, contendo a composição química e os coeficientes de digestibilidade aparente dos nutrientes nas dietas experimentais (ALMEIDA, 1994).

Os dados foram submetidos a um estudo de correlação entre o conteúdo de matéria seca (MS), matéria orgânica (MO), proteína bruta (PB), energia bruta (EB), energia digestível (ED), fibra bruta (FB), fibra em detergente neutro (FDN), fibra em detergente ácido (FDA), celulose (CEL), hemiceluloses (HEM) e lignina (LIG) nas dietas experimentais e os coeficientes de digestibilidade aparente da matéria seca (CDMS), matéria orgânica (CDMO), proteína bruta (CDPB), energia bruta (CDE), fibra bruta (CDFB), fibra em detergente neutro (CDFDN), fibra em detergente ácido (CDFDA), celulose (CDCEL), hemicelulose (CDHEM) e lignina(CDLIG), utilizando o procedimento CORR do programa SAS (SAS, 1990), selecionando-se as melhores correlações entre $\mathrm{ED}, \mathrm{CDE}, \mathrm{CDMO}$ e $\mathrm{CDPB}$ e os componentes químicos das dietas.

Os valores de $\mathrm{CDE}, \mathrm{CDMO}, \mathrm{CDPB}$ e do teor de energia digestível (ED) foram submetidos à análise de regressão linear simples e múltipla, em função dos componentes químicos das dietas experimentais e de duas classes de dietas - dietas simples com alimentos volumosos e dietas mistas com alimentos volumosos e concentrados - utilizando-se os procedimentos GLM e STEPWISE do programa SAS (SAS, 1990). Os modelos foram escolhidos com base no teste dos coeficientes de regressão, adotando-se o nível de $1 \%$ de probabilidade pelo teste $\mathrm{t}$, e dos coeficientes de determinação.

\section{Resultados e Discussão}

Os valores médios da composição química expressa na matéria seca, do conteúdo de energia bruta e digestível e dos coeficientes de digestibilidade aparente dos nutrientes em cada dieta experimental, para eqüinos compilados da literatura, estão citados na Tabela 1 .

Os valores médios da composição química obtidos para os alimentos volumosos, de forma geral, são 
1270 Rev. bras. zootec.

Tabela 1 - Valores médios da composição química expressa na matéria seca, do conteúdo em energia bruta (EB) e digestível (ED), dos coeficientes de digestibilidade aparente da matéria seca (MS), matéria orgânica (MO), proteína bruta (PB), energia bruta (EB), fibra bruta (FB), fibra em detergente neutro (FDN), fibra em detergente ácido (FDA), celulose (CEL), hemiceluloses (HEM) e lignina (LIG), em dietas para eqüinos

Table 1 - Average values of chemical composition, gross energy (GE) and digestible energy (DE) contents and apparent digestibility coefficients of dry matter (DM), organic matter (OM), crude protein (CP), gross energy (GE), crude fiber (CF), neutral detergent fiber (NDF), acid detergent fiber (ADF), cellulose (CEL), hemicelluloses (HEM) and lignin (LIG), in dry matter basis, of diets horses diets

\begin{tabular}{|c|c|c|c|c|c|c|c|c|c|c|c|}
\hline Dieta & $\begin{array}{l}\mathrm{MS} \\
(\%)\end{array}$ & $\begin{array}{l}\mathrm{MO} \\
(\%)\end{array}$ & $\begin{array}{l}\mathrm{PB} \\
(\%)\end{array}$ & $\begin{array}{c}\mathrm{EB} \\
(\mathrm{Mcal} / \mathrm{kg})\end{array}$ & $\begin{array}{c}\mathrm{ED} \\
\text { (Mcal/kg) }\end{array}$ & $\begin{array}{l}\mathrm{FB} \\
(\%)\end{array}$ & $\begin{array}{l}\text { FDN } \\
(\%)\end{array}$ & $\begin{array}{l}\text { FDA } \\
(\%)\end{array}$ & $\begin{array}{l}\text { CEL } \\
(\%)\end{array}$ & $\begin{array}{c}\mathrm{HEM} \\
(\%)\end{array}$ & $\begin{array}{l}\mathrm{LIG} \\
(\%)\end{array}$ \\
\hline Diet & $D M$ & $O M$ & $C P$ & $G E$ & $D E$ & $C F$ & $M D F$ & $A D F$ & $C E L$ & HEM & $L I G$ \\
\hline Alfafa $(\mathrm{n}=43)$ & 86,61 & 89,06 & 18,93 & 4,13 & 2,33 & 33,09 & 47,15 & 35,61 & 27,22 & 11,39 & 8,95 \\
\hline $\begin{array}{l}\text { (Medicago sativa })^{1} \\
\text { Lucerne }\end{array}$ & 59,48 & 56,60 & 70,29 & 54,80 & - & 43,77 & 43,66 & 37,91 & 54,72 & 44,88 & 10,60 \\
\hline Trevo-vermelho $(\mathrm{n}=3)$ & 89,53 & 91,30 & 14,07 & 4,35 & 2,05 & 32,73 & 56,20 & 37,83 & 33,25 & 14,37 & 5,45 \\
\hline $\begin{array}{l}(\text { Trifolium pratense) })^{1} \\
\text { Clover, red }\end{array}$ & - & 55,37 & - & 45,40 & - & 44,37 & 46,15 & 41,15 & 49,5 & 52,65 & $-6,95$ \\
\hline Grama Brome $(\mathrm{n}=5)$ & 89,72 & 92,38 & 10,72 & 4,46 & 1,95 & 38,28 & 64,74 & 39,18 & 36,30 & 24,10 & 4,40 \\
\hline $\begin{array}{l}(\text { Bromus inermis })^{1} \\
\text { Brome, smooth }\end{array}$ & 45,83 & 47,40 & 49,18 & 44,00 & - & 44,6 & 45,4 & 36 & 43,1 & 56,8 & 7,10 \\
\hline Aveia forrageira $(\mathrm{n}=2)$ & 85,10 & 92,10 & 9,60 & 4,26 & 1,91 & 32,00 & 65,75 & 45,50 & - & 15,75 & - \\
\hline $\begin{array}{l}(\text { Avena sativa })^{1} \\
\text { Oats }\end{array}$ & 45,55 & - & 60,95 & 44,80 & - & - & 44,3 & 38,95 & - & - & - \\
\hline $\begin{array}{l}\text { Timóteo }(\mathrm{n}=10) \\
(\text { Phleum pratense })^{1} \\
\text { Thimothy }\end{array}$ & $\begin{array}{l}91,45 \\
54,12\end{array}$ & $\begin{array}{l}93,97 \\
47,45\end{array}$ & $\begin{array}{r}7,30 \\
49,05\end{array}$ & $\begin{array}{l}4,46 \\
47,63\end{array}$ & $\begin{array}{c}1,96 \\
-\end{array}$ & $\begin{array}{l}41,71 \\
49,73\end{array}$ & $\begin{array}{l}68,10 \\
45,03\end{array}$ & $\begin{array}{c}40,64 \\
39,5\end{array}$ & $\begin{array}{l}30,85 \\
49,59\end{array}$ & $\begin{array}{l}26,89 \\
51,27\end{array}$ & $\begin{array}{l}7,30 \\
8,27\end{array}$ \\
\hline $\begin{array}{l}\text { Grama-canário }(\mathrm{n}=7) \\
(\text { Phalaris arundinacea) } \\
\text { Canarygrass, reed }\end{array}$ & $\begin{array}{l}89,96 \\
47,14\end{array}$ & $\begin{array}{l}92,59 \\
47,55\end{array}$ & $\begin{array}{c}9,79 \\
53,84\end{array}$ & $\begin{array}{l}4,36 \\
41,77\end{array}$ & $\begin{array}{c}1,91 \\
-\end{array}$ & $\begin{array}{c}35,69 \\
43,2\end{array}$ & $\begin{array}{l}66,64 \\
38,63\end{array}$ & $\begin{array}{c}38,37 \\
31,1\end{array}$ & $\begin{array}{l}34,00 \\
44,27\end{array}$ & $\begin{array}{c}26,81 \\
44,5\end{array}$ & $\begin{array}{c}3,75 \\
15,00\end{array}$ \\
\hline $\begin{array}{l}\text { Grama-fescue }(\mathrm{n}=4) \\
(\text { Festuca arundinacea })^{1} \\
\text { Fescuegrass }\end{array}$ & $\begin{array}{l}90,30 \\
46,55\end{array}$ & $\begin{array}{l}93,10 \\
45,70\end{array}$ & $\begin{array}{c}8,95 \\
47,85\end{array}$ & $\begin{array}{c}4,38 \\
39,30\end{array}$ & $\begin{array}{c}1,84 \\
-\end{array}$ & $\begin{array}{c}38,40 \\
42,8\end{array}$ & $\begin{array}{l}70,18 \\
40,05\end{array}$ & $\begin{array}{c}39,88 \\
36,5\end{array}$ & $\begin{array}{c}36,40 \\
41,1\end{array}$ & $\begin{array}{l}28,43 \\
44,25\end{array}$ & $\begin{array}{l}4,40 \\
2,15\end{array}$ \\
\hline $\begin{array}{l}\text { Capim Bermuda }(\mathrm{n}=6) \\
(\text { Cynodon dactylon })^{1} \\
\text { Bermudagrass }\end{array}$ & $\begin{array}{l}91,48 \\
45,10\end{array}$ & $\begin{array}{l}92,38 \\
44,80\end{array}$ & $\begin{array}{c}9,28 \\
46,92\end{array}$ & $\begin{array}{c}3,39 \\
43,17\end{array}$ & $\begin{array}{c}1,95 \\
-\end{array}$ & $\begin{array}{l}31,82 \\
43,67\end{array}$ & $\begin{array}{l}72,86 \\
43,87\end{array}$ & $\begin{array}{c}34,48 \\
36,9\end{array}$ & $\begin{array}{c}28,33 \\
42,9\end{array}$ & $\begin{array}{l}37,00 \\
54,73\end{array}$ & $\begin{array}{c}5,03 \\
12,50\end{array}$ \\
\hline $\begin{array}{l}\text { Grama-de-pomar }(\mathrm{n}=9) \\
(\text { Dactylis glomerata })^{1} \\
\text { Orchardgrass }\end{array}$ & $\begin{array}{l}91,10 \\
57,07\end{array}$ & $\begin{array}{l}92,67 \\
44,50\end{array}$ & $\begin{array}{l}10,06 \\
48,65\end{array}$ & $\begin{array}{c}4,40 \\
41,90\end{array}$ & $\begin{array}{c}2,09 \\
-\end{array}$ & $\begin{array}{l}31,86 \\
51,33\end{array}$ & $\begin{array}{c}62,49 \\
44,3\end{array}$ & $\begin{array}{c}35,99 \\
39,5\end{array}$ & $\begin{array}{l}36,10 \\
54,24\end{array}$ & $\begin{array}{l}26,07 \\
50,95\end{array}$ & $\begin{array}{r}4,10 \\
13,70\end{array}$ \\
\hline $\begin{array}{l}\text { Grama-centeio }(\mathrm{n}=7) \\
(\text { Lolium multiflorum })^{1} \\
\text { Ryegrass }\end{array}$ & $\begin{array}{l}77,66 \\
59,20\end{array}$ & $\begin{array}{l}88,70 \\
57,43\end{array}$ & $\begin{array}{l}14,46 \\
53,60\end{array}$ & $\begin{array}{c}4,39 \\
44,20\end{array}$ & $\begin{array}{c}2,03 \\
-\end{array}$ & $\begin{array}{c}29,71 \\
-\end{array}$ & $\begin{array}{c}63,38 \\
49,9\end{array}$ & $\begin{array}{c}38,80 \\
39,4\end{array}$ & - & $\begin{array}{c}24,61 \\
-\end{array}$ & - \\
\hline $\begin{array}{l}\text { Grama-azul }(\mathrm{n}=1) \\
\text { (Poa pratensis) }^{1} \\
\text { Bluegrass }\end{array}$ & $\begin{array}{l}90,00 \\
44,80\end{array}$ & $\begin{array}{c}92,00 \\
-\end{array}$ & $\begin{array}{l}11,30 \\
59,30\end{array}$ & $\begin{array}{c}4,34 \\
44,40\end{array}$ & $\begin{array}{c}1,92 \\
-\end{array}$ & $\begin{array}{c}30,30 \\
-\end{array}$ & $\begin{array}{c}72,70 \\
50,8\end{array}$ & $\begin{array}{c}45,90 \\
39,7\end{array}$ & - & $\begin{array}{c}26,80 \\
-\end{array}$ & - \\
\hline $\begin{array}{l}\text { Capim-elefante }(\mathrm{n}=2) \\
(\text { Penninsetum purpureum })^{1} \\
\text { Elephantgrass }\end{array}$ & $\begin{array}{l}66,65 \\
40,55\end{array}$ & $\begin{array}{l}91,60 \\
41,75\end{array}$ & $\begin{array}{c}5,00 \\
35,50\end{array}$ & $\begin{array}{c}4,29 \\
33,40\end{array}$ & $\begin{array}{c}1,64 \\
-\end{array}$ & - & $\begin{array}{c}78,25 \\
45,3\end{array}$ & $\begin{array}{c}46,95 \\
31,3\end{array}$ & $\begin{array}{c}28,70 \\
30,8\end{array}$ & $\begin{array}{l}31,30 \\
68,65\end{array}$ & $\begin{array}{c}, 90 \\
-\end{array}$ \\
\hline $\begin{array}{l}\text { Mistura de } \text { gramíneas }^{2}(\mathrm{n}=19) \\
\text { CDA }^{1} \\
\text { Grasses }\end{array}$ & $\begin{array}{l}75,77 \\
51,68\end{array}$ & $\begin{array}{l}90,47 \\
58,34\end{array}$ & $\begin{array}{l}13,04 \\
57,55\end{array}$ & $\begin{array}{c}4,35 \\
49,70\end{array}$ & $\begin{array}{c}2,18 \\
-\end{array}$ & $\begin{array}{l}27,18 \\
43,73\end{array}$ & $\begin{array}{l}58,73 \\
51,25\end{array}$ & $\begin{array}{c}43,50 \\
46\end{array}$ & $\begin{array}{c}- \\
48,1\end{array}$ & $\begin{array}{c}30,20 \\
-\end{array}$ & $\begin{array}{l}- \\
-\end{array}$ \\
\hline $\begin{array}{l}\text { Polpa de beterraba }(\mathrm{n}=5) \\
(\text { Beta vulgaris altissima })^{1} \\
\text { Beet sugar }\end{array}$ & $\begin{array}{l}91,00 \\
87,00\end{array}$ & $\begin{array}{l}93,40 \\
79,00\end{array}$ & $\begin{array}{c}10,06 \\
-\end{array}$ & $\begin{array}{c}3,89 \\
73,00\end{array}$ & $\begin{array}{c}2,75 \\
-\end{array}$ & $\begin{array}{c}18,96 \\
-\end{array}$ & $\begin{array}{c}41,70 \\
-\end{array}$ & $\begin{array}{c}25,80 \\
-\end{array}$ & - & $\begin{array}{c}15,90 \\
-\end{array}$ & - \\
\hline $\begin{array}{l}\text { Palhas }^{3}(\mathrm{n}=12) \\
\text { CDA }^{1} \\
\text { Straw }\end{array}$ & $\begin{array}{l}90,95 \\
41,28\end{array}$ & $\begin{array}{l}93,11 \\
37,71\end{array}$ & $\begin{array}{c}4,19 \\
28,60\end{array}$ & $\begin{array}{c}4,41 \\
40,83\end{array}$ & $\begin{array}{c}1,62 \\
-\end{array}$ & $\begin{array}{l}42,38 \\
34,23\end{array}$ & $\begin{array}{l}80,27 \\
41,13\end{array}$ & $\begin{array}{l}52,39 \\
43,26\end{array}$ & $\begin{array}{l}42,08 \\
46,48\end{array}$ & $\begin{array}{c}29,88 \\
31,5\end{array}$ & $\begin{array}{r}9,97 \\
-2,05\end{array}$ \\
\hline $\begin{array}{l}\text { Capim-elefante }+ \\
\text { Cana-de-açúcar }(\mathrm{n}=3) \\
(P . \text { purpureum }+ \text { Saccharum } \\
\text { officinarum })^{1} \\
\text { Elephantgrass }+ \text { Sugar-cane } \\
\end{array}$ & 48,47 & 93,13 & 57,40 & - & - & - & 70,07 & 45,67 & 37,13 & 58,37 & 9,30 \\
\hline
\end{tabular}


Continuação da Tabela $1 . .$.

\begin{tabular}{|c|c|c|c|c|c|c|c|c|c|c|c|}
\hline Dieta & $\begin{array}{l}\text { MS } \\
(\%)\end{array}$ & $\begin{array}{l}\mathrm{MO} \\
(\%)\end{array}$ & $\begin{array}{l}\mathrm{PB} \\
(\%)\end{array}$ & $\begin{array}{c}\mathrm{EB} \\
(\mathrm{Mcal} / \mathrm{kg})\end{array}$ & $\begin{array}{c}\mathrm{ED} \\
(\mathrm{Mcal} / \mathrm{kg})\end{array}$ & $\begin{array}{l}\mathrm{FB} \\
(\%)\end{array}$ & $\begin{array}{c}\mathrm{FDN} \\
(\%)\end{array}$ & $\begin{array}{c}\text { FDA } \\
(\%)\end{array}$ & $\begin{array}{l}\mathrm{CEL} \\
(\%)\end{array}$ & $\begin{array}{c}\mathrm{HEM} \\
(\%)\end{array}$ & $\begin{array}{l}\mathrm{LIG} \\
(\%)\end{array}$ \\
\hline Diet & $D M$ & $O M$ & $C P$ & $G E$ & $D E$ & $C F$ & $M D F$ & $A D F$ & $C E L$ & $H E M$ & $L I G$ \\
\hline Alfafa + Palha $(n=2)$ & 90,00 & 92,00 & 12,65 & 4,25 & 1,57 & - & 59,85 & 45,25 & - & 14,60 & - \\
\hline $\mathrm{CDA}^{1}$ & 41,45 & - & 59,85 & 37,05 & - & - & 25,05 & 20,75 & - & - & - \\
\hline \multicolumn{12}{|l|}{ Lucerne + Straw } \\
\hline Alfafa + Gramíneas $(\mathrm{n}=7)$ & 92,43 & 92,43 & 12,06 & 4,17 & 2,26 & - & 57,47 & 31,00 & - & - & - \\
\hline $\begin{array}{l}\text { CDA }^{1} \\
\text { Lucerne + Grasses }\end{array}$ & 63,50 & 50,60 & 59,64 & 56,33 & - & - & 42,27 & 38,33 & - & - & - \\
\hline Silagem de gramíneas $(\mathrm{n}=5)$ & 30,00 & 87,18 & 19,40 & 4,42 & - & 23,88 & 46,82 & - & - & - & - \\
\hline $\begin{array}{l}\mathrm{CDA}^{1} \\
\text { Grass silage }\end{array}$ & - & 71,28 & - & - & - & - & - & - & - & - & - \\
\hline$\overline{\text { Silagem de milho }(\mathrm{n}=4)}$ & 31,13 & 92,28 & 8,33 & 4,54 & 3,10 & 19,40 & 45,70 & 27,80 & - & 17,90 & - \\
\hline $\begin{array}{l}(\text { Zea mays })^{1} \\
\text { Corn silage }\end{array}$ & - & 72,35 & 39,00 & 71,10 & - & 55,2 & - & - & - & - & - \\
\hline Alfafa + Concentrado $(n=64)$ & 91,27 & 91,58 & 13,79 & 4,47 & 2,89 & 19,52 & 41,82 & 27,60 & 22,59 & 18,54 & 5,60 \\
\hline $\begin{array}{l}\text { (Medicago sativa }+ \\
\text { concentrado })^{1} \\
\text { Lucerne }+ \text { Concentrate }\end{array}$ & 63,75 & 67,24 & 70,81 & 59,86 & - & 36,91 & 50,21 & 34,18 & 64,08 & 64,92 & - \\
\hline $\begin{array}{l}\text { Gramíneas }+ \\
\text { Concentrado }(n=93)\end{array}$ & 86,99 & 91,50 & 12,10 & 4,23 & 2,74 & 20,21 & 52,91 & 25,11 & 20,30 & 28,40 & 4,08 \\
\hline $\begin{array}{l}\mathrm{CDA}^{1} \\
\text { Grasses }+ \text { Concentrate }\end{array}$ & 61,34 & 66,44 & 69,88 & 61,46 & - & 40,41 & 48,27 & 37,93 & 49,46 & 59,65 & 26,13 \\
\hline $\begin{array}{l}\text { Palha + Concentrado }(\mathrm{n}=4) \\
\text { CDA }^{1} \\
\text { Straw }+ \text { Concentrate }\end{array}$ & $\begin{array}{l}89,50 \\
52,55\end{array}$ & $\begin{array}{l}90,60 \\
55,20\end{array}$ & $\begin{array}{l}11,15 \\
65,15\end{array}$ & $\begin{array}{l}- \\
-\end{array}$ & $\begin{array}{c}2,50 \\
-\end{array}$ & $\begin{array}{c}31,17 \\
43,3\end{array}$ & $\begin{array}{c}47,00 \\
47,3\end{array}$ & $\begin{array}{l}39,57 \\
40,07\end{array}$ & $\begin{array}{l}33,13 \\
43,97\end{array}$ & $\begin{array}{c}20,10 \\
54,2\end{array}$ & $\begin{array}{l}7,10 \\
-20,30\end{array}$ \\
\hline $\begin{array}{l}\text { Silagem de milho }+ \\
\text { Concentrado }(n=8)\end{array}$ & 68,55 & 90,00 & 16,68 & 4,41 & 3,38 & 14,76 & - & - & - & - & - \\
\hline $\begin{array}{l}\mathrm{CDA}^{1} \\
\text { Corn silage }+ \text { Concentrate }\end{array}$ & - & 79,13 & 45,00 & 76,66 & - & 38,36 & - & - & - & - & - \\
\hline $\begin{array}{l}\text { Concentrado }(\mathrm{n}=34) \\
\text { CDA }^{1} \\
\text { Concentrate }\end{array}$ & $\begin{array}{l}88,03 \\
68,12\end{array}$ & $\begin{array}{l}94,02 \\
78,01\end{array}$ & $\begin{array}{l}12,71 \\
73,77\end{array}$ & $\begin{array}{c}4,30 \\
74,57\end{array}$ & $\begin{array}{c}3,39 \\
-\end{array}$ & $\begin{array}{l}11,59 \\
40,37\end{array}$ & $\begin{array}{l}24,83 \\
44,95\end{array}$ & $\begin{array}{l}12,48 \\
37,09\end{array}$ & $\begin{array}{l}13,91 \\
44,04\end{array}$ & $\begin{array}{l}15,03 \\
45,33\end{array}$ & $\begin{array}{l}3,44 \\
0,91\end{array}$ \\
\hline
\end{tabular}

n - Número de observações

$n$ - Number of observations

1 CDA = Coeficiente de digestibilidade aparente (\%)

1 Apparent digestibility coefficients

2 Gramíneas temperadas

2 Temperate grasses

3 Palhadas de trigo, cevada, aveia e de gramíneas

3 Weat, barley, oat, and grasses straws

semelhantes aos observados no NRC (1989), enquanto os valores médios da composição química e dos coeficientes de digestibilidade da matéria orgânica na silagem de milho e de gramíneas são semelhantes aos observados por MARTIN-ROSSET (1990). Os valores médios da composição química do capim-elefante, dos teores de celulose, hemiceluloses e lignina em todas as dietas e dos coeficientes de digestibilidade aparente dos nutrientes não são citados nas tabelas nutricionais do NRC (1989) e do INRA (MARTIN-ROSSET, 1990), de uso corrente na avaliação de dietas para eqüinos.

Os valores médios, mínimos e máximos da composição química, do conteúdo de energia bruta e digestível e dos coeficientes de digestibilidade aparen- te dos nutrientes nas dietas experimentais, para eqüinos compilados da literatura, estão citados na Tabela 2. Os teores dos nutrientes nas dietas, expressos na matéria seca, variaram de 3,1 a $24,7 \%$ para PB; 2,0 a $76,6 \%$ para FB; 12,6 a $88,6 \%$ para FDN; e 3,7 a $56,7 \%$ para FDA, ao passo que os coeficientes de digestibilidade aparente variaram de 21,0 a $89,3 \%$ para MO; 28,0 a $89,3 \%$ para PB; e 33,4 a 87,0\% para EB.

Os coeficientes de correlação entre os coeficientes de digestibilidade aparente de matéria orgânica, proteína bruta, energia bruta, conteúdo de energia digestível, os teores na matéria seca, proteína bruta, energia bruta, fibra bruta, fibra em detergente neutro, fibra em detergente ácido, celulose, hemiceluloses e lignina e os coeficientes de digestibilidade aparente da 
1272 Rev. bras. zootec.

Tabela 2 - Valores médios, mínimos e máximos da composição química, do conteúdo em energia bruta (EB) e digestível (ED) e dos coeficientes de digestibilidade aparente da matéria seca (CDMS), matéria orgânica (CDMO), proteína bruta (CDPB), energia bruta (CDE), fibra bruta (CDFB), fibra em detergente neutro (CDFDN), fibra em detergente ácido (CDFDA), celulose (CDCEL), hemiceluloses (CDHEM) e lignina (CDLIG), das dietas para eqüinos

Table 2 - Average, minimum and maximum values of chemical composition, gross energy (GE) and digestible energy (ED) contents and apparent digestibility coefficients of dry matter (DMAD), organic matter (OMAD), crude protein (CPAD), energy (EAD), crude fiber (CFAD), gross neutral detergent fiber (NDFAD), acid detergent fiber (ADFAD), cellulose (CELAD), hemicelluloses (HEMAD) and lignin (LIGAD), in horses diets

\begin{tabular}{|c|c|c|c|c|c|}
\hline Item & $\begin{array}{l}\text { Média } \\
\text { Average }\end{array}$ & $\begin{array}{l}\text { Mínima } \\
\text { Minimum }\end{array}$ & $\begin{array}{l}\text { Máxima } \\
\text { Maximum }\end{array}$ & $\mathrm{S}$ & $\mathrm{n}$ \\
\hline & \multicolumn{5}{|c|}{ Composição (\% MS) } \\
\hline & \multicolumn{5}{|c|}{ Composition (\% DM) } \\
\hline Matéria seca & 85,95 & 19,60 & 95,70 & 14,38 & 368 \\
\hline Dry matter & & & & & \\
\hline Matéria orgânica & 91,79 & 79,50 & 99,90 & 3,12 & 328 \\
\hline $\begin{array}{l}\text { Organic matter } \\
\text { Proteína bruta }\end{array}$ & 12,59 & 3,10 & 24,70 & 4,34 & 354 \\
\hline Crude protein & & & & & \\
\hline $\begin{array}{l}\text { Energia bruta (Mcal/kg MS) } \\
\text { Gross energy }\end{array}$ & 4,297 & 1,580 & 9,600 & 0,714 & 174 \\
\hline $\begin{array}{l}\text { Energia digestível (Mcal/kg MS) } \\
\text { Digestible energy }\end{array}$ & 2,501 & 1,500 & 7,200 & 0,713 & 251 \\
\hline Fibra bruta & 26,87 & 2,00 & 76,60 & 10,93 & 220 \\
\hline $\begin{array}{l}\text { Crude fiber } \\
\text { Fibra em detergente neutro } \\
\text { Neutral detergent fiber }\end{array}$ & 53,31 & 12,60 & 88,60 & 14,90 & 201 \\
\hline $\begin{array}{l}\text { Fibra em detergente ácido } \\
\text { Acid detergent fiber }\end{array}$ & 31,93 & 3,70 & 56,70 & 10,23 & 227 \\
\hline $\begin{array}{l}\text { Celulose } \\
\text { Cellulose }\end{array}$ & 24,23 & 2,40 & 43,90 & 9,17 & 88 \\
\hline $\begin{array}{l}\text { Hemiceluloses } \\
\text { Hemicelluloses }\end{array}$ & 20,94 & 4,90 & 39,20 & 8,44 & 189 \\
\hline Lignina & 5,01 & 1,30 & 14,10 & 2,62 & 66 \\
\hline Lignin & \multicolumn{4}{|c|}{ Coeficiente de digestibilidade aparente $(\%)$} & \\
\hline CDMS (DMAD) & 58,71 & 27,80 & 88,20 & 11,90 & 216 \\
\hline $\mathrm{CDMO}(O M A D)$ & 62,78 & 21,00 & 89,30 & 13,04 & 153 \\
\hline $\mathrm{CDPB}(C P A D)$ & 66,73 & 28,00 & 90,80 & 12,10 & 263 \\
\hline $\operatorname{CDE}(E A D)$ & 58,39 & 33,40 & 87,00 & 12,75 & 168 \\
\hline $\mathrm{CDFB}(C F A D)$ & 41,86 & 17,60 & 65,40 & 9,48 & 145 \\
\hline CDFDN (NDFAD) & 45,89 & 16,90 & 71,20 & 8,88 & 110 \\
\hline CDFDA $(A D F A D)$ & 37,32 & 12,80 & 63,90 & 10,27 & 129 \\
\hline $\operatorname{CDCEL}(C E L A D)$ & 49,19 & 30,00 & 81,50 & 10,39 & 99 \\
\hline $\operatorname{CDHEM}(H E M A D)$ & 53,84 & 24,20 & 73,50 & 10,58 & 89 \\
\hline CDLIG (LIGAD) & 5,50 & $-25,10$ & 31,10 & 15,75 & 37 \\
\hline
\end{tabular}

S - Desvio-padrão.

sd - Standard deviation

n - Número de observações.

$n$ - Number of observations.

matéria seca e matéria orgânica, em todas as dietas experimentais, podem ser observados na Tabela 3 .

Pode-se observar que os componentes fibrosos exercem influência negativa sobre o conteúdo de matéria orgânica digestível, proteína digestível e do valor energético dos alimentos e de dietas para eqüinos, ou seja, quanto maior o conteúdo em $\mathrm{FB}$, FDN, FDA, CEL e LIG, menores serão os coeficientes de digestibilidade aparente da matéria orgânica, proteína bruta e energia bruta. Observa-se também que o coeficiente de digestibilidade aparente da matéria orgânica está relacionado de forma negativa aos componentes fibrosos e correlacionado de forma positiva ao conteúdo de energia digestível das dietas. A HEM não se apresentou como bom preditor do valor nutricional ou energético das dietas, uma vez que sua correlação com a digestibilidade da energia e da proteína não foi expressiva. Desta análise, foram 
ALMEIDA et al.

Tabela 3 - Coeficientes de correlação entre os coeficientes de digestibilidade aparente da matéria orgânica (CDMO), proteína bruta (CDPB), energia bruta (CDE), conteúdo em energia digestível (ED) e os teores de proteína bruta (PB), energia bruta (EB), fibra bruta (FB), fibra em detergente neutro (FDN), fibra em detergente ácido (FDA), celulose (CEL), hemiceluloses (HEM), lignina (LIG), na matéria seca, e os coeficientes de digestibilidade aparente da matéria seca (CDMS) e matéria orgânica (CDMO), das dietas para eqüinos

Table 3 - Correlation coefficients among apparent digestibility coefficients of organic matter (OMAD), crude protein (CPAD), gross energy (EAD) and digestible energy content $(D E)$ and crude protein $(C P)$, gross energy (GE), crude fiber (CF), neutral detergent fiber (NDF), acid detergent fiber (ADF), cellulose (CEL), hemicelluloses (HEM) and lignin (LIG) contents in dry matter basis, and apparent digestibility coefficients of dry matter (DMAD) and organic matter (OMAD), in horses diets

\begin{tabular}{|c|c|c|c|c|c|c|c|c|c|c|}
\hline \multirow{3}{*}{ Item } & \multicolumn{9}{|c|}{$\begin{array}{l}\text { Coeficientes de correlação } \\
\text { Correlation coefficients }\end{array}$} & \multirow{3}{*}{$\begin{array}{c}\text { CDMO } \\
(\%)^{1} \\
O M A D\end{array}$} \\
\hline & $\begin{array}{l}\mathrm{PB} \\
(\%)^{1}\end{array}$ & $\begin{array}{l}\mathrm{EB} \\
(\%)^{1}\end{array}$ & $\begin{array}{l}\mathrm{FB} \\
(\%)^{1}\end{array}$ & $\begin{array}{l}\text { FDN } \\
(\%)^{1}\end{array}$ & $\begin{array}{l}\text { FDA } \\
(\%)^{1}\end{array}$ & $\begin{array}{l}\text { CEL } \\
(\%)^{1}\end{array}$ & $\begin{array}{l}\text { HEM } \\
(\%)^{1}\end{array}$ & $\begin{array}{l}\mathrm{LG} \\
(\%)^{1}\end{array}$ & $\begin{array}{l}\text { CDMS } \\
(\%)^{1}\end{array}$ & \\
\hline & $C P$ & $G E$ & $C F$ & $N D F$ & $A D F$ & $C E L$ & HEM & $L I G$ & $D M A D$ & \\
\hline $\begin{array}{l}\overline{\operatorname{CDMO}(\%)} \\
O M A D\end{array}$ & 0,33 & 0,28 & $-0,81$ & $-0,88$ & $-0,93$ & $-0,94$ & $-0,47$ & $-0,67$ & 0,98 & 1,00 \\
\hline $\operatorname{CDPB}(\%)$ & 0,41 & 0,23 & $-0,35$ & $-0,67$ & $-0,65$ & $-0,51$ & $-0,29$ & $-0,40$ & 0,65 & 0,57 \\
\hline $\begin{array}{l}C P A D \\
C D E(\%) \\
E A D\end{array}$ & 0,50 & $-0,04$ & $-0,76$ & $-0,80$ & $-0,89$ & $-0,81$ & $-0,15$ & $-0,41$ & 0,98 & 0,99 \\
\hline $\begin{array}{l}\mathrm{ED}(\mathrm{Mcal} / \mathrm{kg}) \\
D E\end{array}$ & 0,31 & 0,64 & $-0,70$ & $-0,57$ & $-0,62$ & $-0,67$ & $-0,25$ & $-0,37$ & 0,83 & 0,96 \\
\hline
\end{tabular}

${ }^{1} \mathrm{Na}$ base da matéria seca

${ }^{1}$ Dry matter basis.

Tabela 4 - Equações lineares simples, coeficientes de determinação $\left(r^{2}\right)$ para a estimativa do conteúdo em energia digestível $(E D)$, dos coeficientes de digestibilidade aparente da energia (CDE), matéria seca (CDMS), matéria orgânica (CDMO) e proteína bruta (CDPB) em função do CDMO e dos teores de proteína bruta (PB), fibra bruta (FB), fibra em detergente neutro (FDN), fibra em detergente ácido (FDA), celulose (CEL) e lignina (LIG) na matéria seca, em dietas para eqüinos

Table 4 - Simple linear equations, coefficients of determination $\left(r^{2}\right)$ for estimate of digestible energy (de) content, apparent digestibility coefficient of energy (EAD), dry matter (DMAD), organic matter (OMAD) and crude protein (CPAD) in function of OMAD and contents of crude protein (CP), crude fiber (CF), neutral detergent fiber (NDF), acid detergent fiber (ADF), cellulose (CEL), lignin (LIG) in dry matter basis, in horse diets

\begin{tabular}{|c|c|c|c|c|c|c|c|c|c|c|c|c|}
\hline $\begin{array}{l}\text { Equação* } \\
\text { Equation }\end{array}$ & $n$ & $\begin{array}{l}\text { Variável } \\
\text { Variable }\end{array}$ & $\beta 0$ & $\begin{array}{l}\text { CDMO } \\
O M A D\end{array}$ & $\begin{array}{l}\mathrm{PB} \\
C P\end{array}$ & $\begin{array}{l}\mathrm{FB} \\
C F\end{array}$ & $\begin{array}{l}\text { FDN } \\
N D F\end{array}$ & $\begin{array}{l}\text { FDA } \\
A D F\end{array}$ & $\begin{array}{l}\text { CEL } \\
C E L\end{array}$ & $\begin{array}{l}\mathrm{LIG} \\
L I G\end{array}$ & $\mathrm{r}^{2}$ & $\overline{\mathrm{CV}}$ \\
\hline 1 & 91 & $\mathrm{ED}(D E)$ & $-0,1040$ & 0,0416 & - & - & - & - & - & - & 0,85 & $\overline{9,0}$ \\
\hline 2 & 143 & $\mathrm{ED}(D E)$ & 3,0960 & - & - & $-0,0278$ & - & - & - & - & 0,37 & 17,5 \\
\hline 3 & 185 & $\mathrm{ED}(D E)$ & 3,9595 & - & - & - & $-0,0285$ & - & - & - & 0,32 & 24,8 \\
\hline 4 & 181 & $\mathrm{ED}(D E)$ & 3,9598 & - & - & - & - & $-0,0469$ & - & - & 0,45 & 20,8 \\
\hline 5 & 68 & $\mathrm{ED}(D E)$ & 3,9485 & - & - & - & - & - & $-0,0607$ & - & 0,48 & 21,3 \\
\hline 6 & 46 & $\mathrm{ED}(D E)$ & 2,9359 & - & - & - & - & - & - & $-0,1308$ & 0,39 & 16,7 \\
\hline 7 & 72 & $\operatorname{CDE}(E A D)$ & 84,1338 & - & - & $-1,0567$ & - & - & - & - & 0,57 & 15,3 \\
\hline 8 & 94 & $\operatorname{CDE}(E A D)$ & 92,7763 & - & - & - & $-0,6556$ & - & - & - & 0,60 & 13,8 \\
\hline 9 & 125 & $\operatorname{CDE}(E A D)$ & 86,0261 & - & - & - & - & $-0,9495$ & - & - & 0,75 & 10,2 \\
\hline 10 & 44 & $\operatorname{CDE}(E A D)$ & 86,8720 & - & - & - & - & - & $-1,2131$ & - & 0,65 & 12,6 \\
\hline 11 & 41 & $\operatorname{CDE}(E A D)$ & 67,0849 & - & - & - & - & - & - & $-2,9106$ & 0,21 & 17,7 \\
\hline 12 & 158 & CDMS (DMAD) & 89,4081 & - & - & - & $-0,5606$ & - & - & - & 0,60 & 12,2 \\
\hline 13 & 179 & CDMS (DMAD) & 84,3955 & - & - & - & - & $-0,7887$ & - & - & 0,62 & 11,8 \\
\hline 14 & 124 & $\mathrm{CDMO}(O M A D)$ & 87,6301 & - & - & $-0,9826$ & - & - & - & - & 0,66 & 11,9 \\
\hline 15 & 82 & $\mathrm{CDMO}(O M A D)$ & 91,6832 & - & - & - & $-0,5925$ & - & - & - & 0,68 & 11,9 \\
\hline 16 & 77 & $\mathrm{CDMO}(O M A D)$ & 89,9290 & - & - & - & - & $-0,9098$ & - & - & 0,83 & 8,6 \\
\hline 17 & 31 & $\mathrm{CDMO}(O M A D)$ & 89,0107 & - & - & - & - & - & $-1,0916$ & - & 0,89 & 7,8 \\
\hline 18 & 31 & $\mathrm{CDMO}(O M A D)$ & 72,2717 & - & - & - & - & - & - & $-2,9310$ & 0,41 & 18,1 \\
\hline 19 & 277 & $\operatorname{CDPB}(C P A D)$ & 46,3508 & - & 1,581 & - & - & - & - & - & 0,30 & 15,4 \\
\hline 20 & 154 & $\mathrm{CDPB}(C P A D)$ & 91,6051 & - & - & - & $-0,5258$ & - & - & - & 0,43 & 14,6 \\
\hline 21 & 186 & $\mathrm{CDPB}(C P A D)$ & 85,2672 & - & - & - & - & $-0,6827$ & - & - & 0,32 & 14,6 \\
\hline
\end{tabular}


selecionados os coeficientes de correlação superiores a 0,60 entre os teores de FB, FDN, FDA, CEL, LIG, CDMS e CDMO e os coeficientes de digestibilidade da matéria orgânica, energia e do conteúdo de energia digestível, nas dietas, que pudessem explicar a influência de determinado nutriente na digestibilidade e na energia digestível destas dietas. Foram também selecionados os coeficientes de correlação entre o CDPB e os teores de proteína bruta $(\mathrm{r}=0,41)$, fibra em detergente neutro $(\mathrm{r}=-0,67)$ e fibra em detergente ácido $(\mathrm{r}=-0,65)$, nas dietas.

A análise de regressão linear simples dos coeficientes de digestibilidade aparente da matéria seca, matéria orgânica, energia, proteína bruta e do conteúdo de energia digestível, em função do CDMO e dos teores de proteína bruta, fibra bruta, fibra em detergente neutro, fibra em detergente ácido, celulose e lignina, na matéria seca, em todas as dietas, resultou em equações para a predição do conteúdo de $\mathrm{ED}, \mathrm{CDE}$, CDMS, CDMO e CDPB (Tabela 4).

A equação de regressão linear simples mais acurada para a predição do conteúdo de energia digestível foi a equação 1, que estimou a ED em função do CDMO $\left(r^{2}=85 \%, C V=9,0 \%\right)$, ao passo que, para a predição do coeficiente de digestibilidade aparente da energia, a equação 9 se mostrou mais acurada, estimando o CDE em função do teor de FDA $\left(r^{2}=75 \%, C V=10,2 \%\right)$. A predição do coeficiente de digestibilidade aparente da matéria orgânica nas dietas para eqüinos pode ser obtida pelas equações 16 e 17, que estimam o CDMO em função do teor de FDA $\left(\mathrm{r}^{2}=83 \%, \mathrm{CV}=8,6 \%\right)$ e CEL $\left(\mathrm{r}^{2}=89 \%, \mathrm{CV}=7,8 \%\right)$, respectivamente. OLSSON e RUUDVERE (1955), em estudo estatístico com os resultados de 1094 ensaios de digestão em eqüinos, nos quais o teor de FB nas dietas variou de 2 a $48 \%$, propuseram uma equação para a estimativa do CDMO, em função do teor de FB nas dietas, sendo CDMO $(\%)=99,71-3,066 \mathrm{FB}+0,0679 \mathrm{FB}^{2}-$ $0,00056 \mathrm{FB}^{3}$.

As equações de predição do coeficiente de digestibilidade aparente da proteína bruta, que estimaram o CDPB em função dos teores de PB, FDN e FDA nas dietas, apresentaram coeficientes de determinação baixos, 30, 43 e 32\%, respectivamente, indicando não serem adequadas para a estimativa do $\mathrm{CDPB}$, no conjunto das dietas avaliadas. As equações obtidas confirmam que há relação direta e negativa entre o conteúdo fibroso da dieta e o seu valor energético e nutricional, e que o conteúdo energético é diretamente relacionado ao conteúdo nutritivo da dieta.
A análise de regressão linear múltipla dos coeficientes de digestibilidade aparente da matéria orgânica, energia bruta e do conteúdo de energia digestível, em função dos teores de matéria orgânica, proteína bruta, fibra em detergente ácido, celulose, na matéria seca, em todas as dietas, resultaram em equações para a estimativa do conteúdo de ED, citadas na Tabela 5.

A equação 22 foi a mais acurada para a predição do conteúdo de energia digestível, visto que estima o conteúdo de ED em função do teor de MO e FDA $\left(\mathrm{R}^{2}=89 \%\right)$. Duas outras equações de regressão múltipla para predição do conteúdo de energia digestível, equações 23 e 24, estimam o conteúdo de ED em função do teor de FDA, com coeficientes de determinação de 78 e $87 \%$, respectivamente. A inclusão da MO não alterou o erro em razão do efeito de FDA, isto é, o erro em razão de FDA nas equações

Tabela 5 - Equações lineares múltiplas e coeficientes de determinação $\left(R^{2}\right)$ para a estimativa do conteúdo de energia digestível (ED), em função dos teores de matéria orgânica (MO) e fibra em detergente ácido (FDA) na matéria seca, em dietas para eqüinos

Table 5 - Multiple linear equations and determination coefficients $\left(R^{2}\right)$ for estimate of the digestible energy (DE) contents in function of organic matter (OM) and acid detergent fiber (ADF) contents in dry matter basis, of horses diets

\begin{tabular}{lcccccc}
\hline $\begin{array}{l}\text { Equação } \\
\text { Equation }\end{array}$ & $\mathrm{n}$ & $\begin{array}{c}\text { Variável* } \\
\text { Variable }\end{array}$ & $\beta 0$ & $\mathrm{MO}$ & $\mathrm{FDA}$ & $\mathrm{R}^{2}$ \\
\hline 22 & 36 & $\mathrm{ED}$ & 5,0285 & $-0,0144$ & $-0,042$ & 0,89 \\
23 & 41 & $\mathrm{ED}$ & 3,7403 & - & $-0,044$ & 0,78 \\
24 & 36 & $\mathrm{ED}$ & 3,7868 & - & $-0,044$ & 0,87 \\
\hline$*(\mathrm{P}<0,01)$. & & & & \\
$\mathrm{n}-$ Número de observações. & & & & \\
$n-$ Number of observations. \\
ED (DE).
\end{tabular}

de regressão 23 e 24 foi igual a $-0,044$ e o erro em razão de FDA na equação de regressão 22, -0,042, demonstrando que não houve interação entre $\mathrm{MO}$ e FDA. Comparando-se as equações 23 e 24, observase que a redução de apenas cinco dados entre as duas elevou o valor do coeficiente de determinação, indicando que os dados eliminados poderiam ser tendenciosos.

FONNESBECK (1981) estabeleceu equações de regressão linear múltipla, a fim de estimar o conteúdo de ED e NDT, em função dos teores de PB, FB, EE, ENN, FDN, FDA e NDT em dietas para eqüinos, obtendo as seguintes equações com os maiores coeficientes de determinação: ED (Mcal/kg $\mathrm{MS})=4,22-0,11 \mathrm{FDA}+0,332 \mathrm{~PB}+0,00112(\mathrm{FDA})^{2}$ $\left(\mathrm{R}^{2}=0,80\right)$ e $\mathrm{ED}(\mathrm{Mcal} / \mathrm{kg} \mathrm{MS})=4,07-0,055 \mathrm{FDA}$ 
ALMEIDA et al.

Tabela 6 - Equações lineares simples, coeficientes de determinação $\left(r^{2}\right)$ para a estimativa do conteúdo de energia digestível (ED), dos coeficientes de digestibilidade aparente da energia (CDE), matéria seca (CDMS), matéria orgânica (CDMO) e proteína bruta (CDPB), em função do CDMO e dos teores de proteína bruta (PB), fibra bruta (FB), fibra em detergente neutro (FDN), fibra em detergente ácido (FDA), celulose (CEL) e lignina (LIG) na matéria seca, em dietas exclusivas com alimentos volumosos e dietas mistas com alimentos volumosos e concentrados para eqüinos

Table 6 - Simple linear equations, coefficients of determination $\left(r^{2}\right)$ for estimate of digestible energy (DE) contents, apparent digestibility coefficient of energy (EAD), dry matter (DMAD), organic matter (OMAD) and crude protein (CPAD) in function of OMAD and contents of crude protein (CP), crude fiber (CF), neutral detergent fiber (NDF), acid detergent fiber (ADF), cellulose (CEL), lignin (LIG) in dry matter basis, of roughage and mixed diets for horses

\begin{tabular}{|c|c|c|c|c|c|c|c|c|c|c|c|c|}
\hline $\begin{array}{l}\text { Equação* } \\
\text { Equation }\end{array}$ & $n$ & $\begin{array}{l}\text { Variável } \\
\text { Variable }\end{array}$ & $\beta 0$ & $\begin{array}{l}\text { CDMO } \\
O M A D \\
\end{array}$ & $\begin{array}{l}\mathrm{PB} \\
C P\end{array}$ & $\begin{array}{l}\text { FB } \\
C F\end{array}$ & $\begin{array}{l}\text { FDN } \\
N D F \\
\end{array}$ & $\begin{array}{l}\text { FDA } \\
A D F\end{array}$ & $\begin{array}{l}\text { CEL } \\
C E L \\
\end{array}$ & $\begin{array}{l}\text { LIG } \\
L I G \\
\end{array}$ & $\mathrm{r}^{2}$ & $\mathrm{CV}$ \\
\hline 25 & 58 & $\mathrm{ED}(D E)$ & 0,2273 & 0,0352 & - & - & - & - & - & - & 0,70 & \\
\hline 26 & 133 & $\mathrm{ED}(D E)$ & 3,2074 & - & - & - & 0,0181 & - & - & - & 0,48 & 11,7 \\
\hline 27 & 135 & $\mathrm{ED}(D E)$ & 3,6022 & - & - & - & - & $-0,0383$ & - & - & 0,57 & 10,7 \\
\hline 28 & 31 & $\mathrm{ED}(D E)$ & 2,6717 & - & - & - & - & - & $-0,0234$ & - & 0,32 & 9,9 \\
\hline 29 & 54 & $\operatorname{CDE}(E A D)$ & 79,735 & - & - & - & $-0,4830$ & - & - & - & 0,41 & 16,2 \\
\hline 30 & 59 & $\operatorname{CDE}(E A D)$ & 86,6409 & - & - & - & - & $-0,9457$ & - & - & 0,56 & 13,9 \\
\hline 31 & 66 & $\mathrm{CDMO}(O M A D)$ & 89,2454 & - & - & $-1,0361$ & - & - & - & - & 0,53 & 14,3 \\
\hline 32 & 67 & $\operatorname{CDMO}(O M A D)$ & 83,5066 & - & - & - & $-0,4737$ & - & - & - & 0,53 & 12,1 \\
\hline 33 & 57 & $\mathrm{CDMO}(O M A D)$ & 86,8171 & - & - & - & - & $-0,8352$ & - & - & 0,54 & 10,5 \\
\hline 34 & 21 & $\mathrm{CDMO}(O M A D)$ & 67,5757 & - & - & - & - & - & $-0,5188$ & - & 0,31 & 7,7 \\
\hline 35 & 96 & $\mathrm{CDPB}(C P A D)$ & 38,2446 & - & 1,7381 & - & - & - & - & - & 0,53 & 14,7 \\
\hline 36 & 86 & $\mathrm{CDPB}(C P A D)$ & 102,059 & - & - & - & $-0,7139$ & - & - & - & 0,52 & 14,5 \\
\hline 37 & 33 & $\mathrm{ED}(D E)$ & $-0,3803$ & 0,0459 & $\begin{array}{c}\text { ietas mi } \\
-\end{array}$ & $\begin{array}{c}\text { istas }(M i x \\
-\end{array}$ & $\begin{array}{c}\text { ddiets) } \\
-\end{array}$ & - & - & - & 0,86 & 7,3 \\
\hline 38 & 27 & $\operatorname{CDE}(E A D)$ & 80,6658 & - & - & $-0,9067$ & - & - & - & - & 0,37 & 16 \\
\hline 39 & 40 & $\mathrm{CDE}(E A D)$ & 98,1285 & - & - & - & $-0,7077$ & - & - & - & 0,62 & 8,8 \\
\hline 40 & 66 & $\operatorname{CDE}(E A D)$ & 90,3526 & - & - & - & - & $-1,1551$ & - & - & 0,79 & 6,8 \\
\hline 41 & 63 & CDMS (DMAD) & 92,2487 & - & - & - & $-0,6489$ & - & - & - & 0,71 & 7,7 \\
\hline 42 & 58 & $\mathrm{CDMO}(O M A D)$ & 86,1526 & - & - & $-0,8967$ & - & - & - & - & 0,54 & 9,8 \\
\hline 43 & 15 & $\mathrm{CDMO}(O M A D)$ & 95,4791 & - & - & - & $-0,5558$ & - & - & - & 0,70 & 7,1 \\
\hline 44 & 20 & $\mathrm{CDMO}(O M A D)$ & 90,8290 & - & - & - & - & $-0,9379$ & - & - & 0,92 & 4,4 \\
\hline 45 & 10 & $\operatorname{CDMO}(O M A D)$ & 88,9743 & - & - & - & - & - & $-0,9561$ & - & 0,96 & 3,1 \\
\hline 46 & 10 & $\operatorname{CDMO}(O M A D)$ & 84,8783 & - & - & - & - & - & - & $-4,5545$ & 0,90 & 5,0 \\
\hline
\end{tabular}

$\left(R^{2}=0,85\right)$. Estas equações foram adotadas pelo NRC (1989) para a predição do conteúdo de ED em alimentos volumosos e concentrados, respectivamente. HINTZ et al. (1992) propuseram, para a aveia, uma equação de regressão para predizer o conteúdo de ED, em função do teor de FDA, sendo ED (Mcal/kg MS) $=4,78-0,095$ FDA.

A análise de regressão linear simples dos coeficientes de digestibilidade aparente da matéria seca, matéria orgânica, energia e proteína bruta e do conteúdo de energia digestível, em função do CDMO e dos teores de proteína bruta, fibra bruta, fibra em detergente neutro, fibra em detergente ácido, celulose e lignina, na matéria seca, em duas classes de dietas, dietas simples com alimentos volumosos e dietas mistas com alimentos volumosos e concentrados, resultou em equações para a estimativa do conteúdo de ED, CDE, CDMS, CDMO e CDPB (Tabela 6).

Nas dietas simples com alimentos volumosos, a equação de regressão linear simples mais acurada para a estimativa do conteúdo de energia digestível foi a 25, que estima a ED em função do CDMO $\left(\mathrm{r}^{2}=70 \%, \mathrm{CV}=9,9 \%\right)$. Segundo ROBINSON e SLADE (1974), a digestibilidade de todos os nutrientes das forragens decresce com o aumento do teor de FB, sendo o conteúdo de FB o melhor preditor simples para todos os coeficientes de digestibilidade, enquanto a inclusão de outros fatores aumenta relativamente pouco a acurácia das equações de predição de digestibilidade. No presente trabalho, a equação de 
regressão do conteúdo de $\mathrm{ED}$, em função do teor de $\mathrm{FB}$, em dietas volumosas, não foi significativa $(\mathrm{P}>0,01)$. Nas equações de regressão do conteúdo de ED, em função dos teores de FDN, FDA e CEL, os coeficientes de determinação apresentaram-se reduzidos.

A predição do coeficiente de digestibilidade aparente da proteína bruta pode ser obtida com a equação 35 , que estima o CDPB em função do teor de PB $\left(\mathrm{r}^{2}\right.$ $=53 \%, \mathrm{CV}=14,7 \%$ ), nas dietas volumosas. VANDER NOOT e TROUT (1971) observaram correlação positiva entre o teor de PB e o CDPB, em ensaios de digestão com eqüinos, e propuseram uma equação de regressão múltipla que estima o CDPB em função do teor de $\mathrm{PB}$ em alimentos volumosos, gramíneas e leguminosa, sendo a equação: CDPB $(\%)=31,63+$ $2,45 \mathrm{~PB}\left(\mathrm{R}^{2}=0,88\right)$. O NRC (1989) estima o CDPB, em fenos de gramíneas, com a equação: CDPB (\%) $=-2,5+0,74$ PB.

Nas dietas mistas com alimentos volumosos e concentrados, a equação de regressão linear simples mais acurada para a predição do conteúdo de energia digestível foi a equação 37, que estima a ED em função do $\mathrm{CDMO}\left(\mathrm{r}^{2}=86 \%, \mathrm{CV}=7,3 \%\right)$, ao passo que para a predição do coeficiente de digestibilidade aparente da matéria orgânica, as equações 44, 45 e 46 mostraram-se acuradas, estimando o CDMO em função dos teores de FDA $\left(r^{2}=92 \%, C V=4,4 \%\right), \operatorname{CEL}\left(r^{2}=96 \%\right.$, $\mathrm{CV}=3,1 \%)$ e LIG $\left(\mathrm{r}^{2}=90 \%, \mathrm{CV}=5,0 \%\right)$.

DACCORD e VUIGNIER (1991) estabeleceram equações de predição da ED em função dos teores de FB e PB, na matéria orgânica, em dietas completas, nas quais a estimativa da energia digestível pode ser

Tabela 7 - Estimativa do conteúdo em energia digestível (ED) e proteína digestível (PD) do capim-elefante e dos fenos de alfafa e capim coast-cross em função do coeficiente de digestibilidade aparente da matéria orgânica (CDMO) e dos conteúdos de energia bruta (EB), proteína bruta (PB), fibra bruta (FB), fibra em detergente ácido (FDA), na matéria seca, e comparação com os valores obtidos por ALMEIDA et al. (1999)

Table 7 - Estimate of digestible energy (DE) and digestible protein (DP) contents of elephant grass, alfalfa and coast-cross grass hays in function of apparent digestibility coefficient of organic matter (OMAD) and gross energy (GE), crude protein (CP), crude fibre (CF), acid detergent fiber (ADF) contents in dry matter basis, and comparison with the values obtained by ALMEIDA et al (1999)

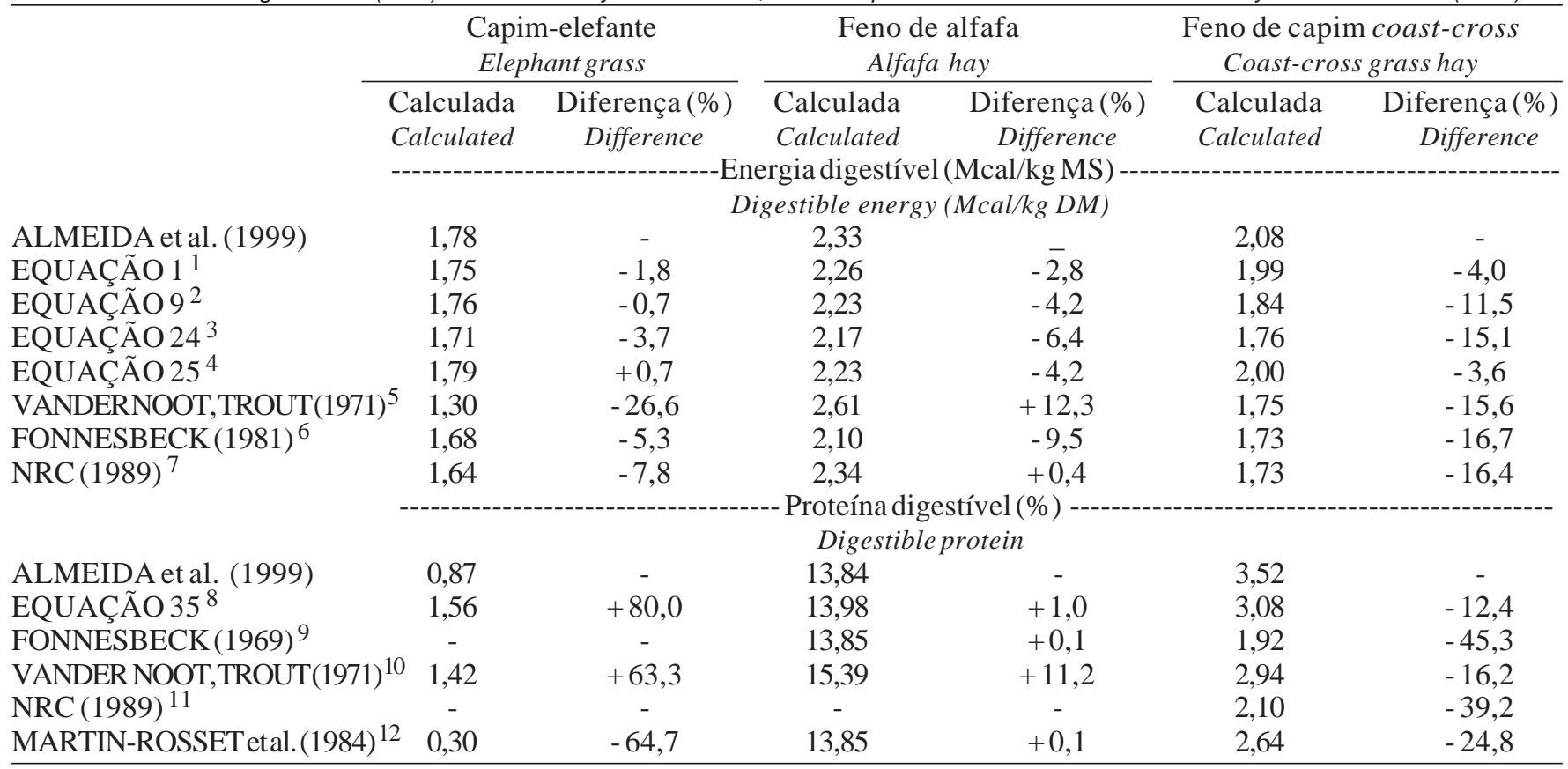

\footnotetext{
$\mathrm{ED}=-0,1040+0,0416 \mathrm{CDMO}\left(\mathrm{r}^{2}=0,85\right)$

$\operatorname{CDE}(\%)=86,0261-0,9495$ FDA $\left(r^{2}=0,75\right) \Rightarrow \mathrm{ED}=\mathrm{EB} \times \mathrm{CDE} / 100$

$\mathrm{ED}=3,7868-0,044 \mathrm{FDA}\left(\mathrm{R}^{2}=0,87\right)$

$\mathrm{ED}=0,2273+0,0352 \mathrm{CDMO}\left(\mathrm{r}^{2}=0,70\right)$

$\operatorname{CDE}(\%)=145,31-2,82 \mathrm{FB}\left(\mathrm{R}^{2}=0,71\right) \Rightarrow \mathrm{ED}=\mathrm{EB} \times \mathrm{CDE} / 100$

$\mathrm{ED}=3,57-0,04 \mathrm{FDA}\left(\mathrm{R}^{2}=0,75\right)$

$\mathrm{ED}=4,22-0,11 \mathrm{FDA}+0,332 \mathrm{~PB}+0,00112(\mathrm{FDA})^{2}\left(\mathrm{R}^{2}=0,80\right)$

CDPB $(\%)=38,2446+1,7381 \mathrm{~PB}\left(\mathrm{r}^{2}=0,53\right) \Rightarrow \mathrm{PD}=\mathrm{PB} \times \mathrm{CDPB} / 100$

$\mathrm{PD}=-3,2+0,817 \mathrm{~PB}\left(\mathrm{r}^{2}=0,88\right)$. Feno de forragem (Roughage hay).

$0 \quad \mathrm{CDPB}(\%)=31,63+2,45 \mathrm{~PB}\left(\mathrm{R}^{2}=0,88\right) \Rightarrow \mathrm{PD}=\mathrm{PB} \times \mathrm{CDPB} / 100$

$11 \operatorname{CDPB}(\%)=-2,5+0,74 \mathrm{~PB} \Rightarrow \mathrm{PD}=\mathrm{PB} \times \mathrm{CDPB} / 100$. Feno de gramíneas (Grasses hay)

$12 \mathrm{PD}(\mathrm{g} / \mathrm{kg} \mathrm{MS})=-27,33+0,8614 \mathrm{~PB}\left(\mathrm{r}^{2}=0,96\right)$. Forragem verde (Fresh roughage).

$\mathrm{PD}(\mathrm{g} / \mathrm{kg} \mathrm{MS})=-29,95+0,8673 \mathrm{~PB}\left(\mathrm{r}^{2}=0,93\right)$. Feno de leguminosas (Legumes hay).

$\mathrm{PD}(\mathrm{g} / \mathrm{kg} \mathrm{MS})=-25,96+0,8357 \mathrm{~PB}\left(\mathrm{r}^{2}=0,96\right)$. Feno de gramíneas (Grasses hay).
} 
obtida com as equações: $\mathrm{ED}(\mathrm{MJ} / \mathrm{kg} \mathrm{MO})=16,73-$ $0,021 \mathrm{FB}(\mathrm{r}=0,98)$ e $\mathrm{ED}(\mathrm{MJ} / \mathrm{kg} \mathrm{MO})=15,57+0,006$ $\mathrm{PB}-0,020 \mathrm{FB}(\mathrm{r}=0,98)$, sendo os valores expressos na matéria orgânica, a fim de evitar interferências, devido à variação no teor de cinzas das dietas.

A estimativa do conteúdo de energia digestível e proteína digestível no capim-elefante e nos fenos de alfafa e capim coast-cross e a comparação dos valores estimados com os valores obtidos por ALMEIDA et al. (1999) podem ser observados na Tabela 7. Segundo ALMEIDA et al. (1999), os teores de PB, FB, FDA e CEL, os conteúdos de EB e ED, na matéria seca, e o CDMO dos alimentos volumosos obtidos em ensaio de digestão com eqüinos adultos foram, respectivamente, 3,$53 ; 40,70 ; 47,12$; e $40,74 \%, 4,278$ e $1,780 \mathrm{Mcal} / \mathrm{kg}$ e $44,50 \%$ para o capim-elefante; 19,$43 ; 30,23 ; 36,54 ;$ e 26,93\%,4,360 e $2,330 \mathrm{Mcal} / \mathrm{kg}$ e $56,90 \%$ para o feno de alfafa; e 6,$27 ; 37,21 ; 45,97 ;$ e $39,02 \%, 4,343$ e 2,080 Mcal/kg e $50,50 \%$ para o feno de capim coast-cross.

A aplicação das equações 1 e 25 descritas no presente trabalho resulta em estimativas eficientes dos conteúdos de energia digestível do capim-elefante e dos fenos de alfafa e capim coast-cross. As estimativas da ED obtidas com as equações 9 e 24 foram adequadas para o capim-elefante e feno de alfafa, porém subestimam, respectivamente, em 11,5e $15,1 \%$ o conteúdo de ED do feno de capim coast-cross, semelhante ao observado com as estimativas resultantes da equação proposta pelo NRC (1989). Os valores estimados com as equações propostas por VANDER NOOT e TROUT (1971) e FONNESBECK (1981) foram inadequados, subestimando ou superestimandoo conteúdo de energia digestível dos alimentos avaliados.

O coeficiente de digestibilidade aparente da matéria orgânica dos alimentos pode ser obtido em tabelas nutricionais ou com uso de equações de predição. A equação 17 obtida no presente trabalho estima o CDMO em 44,53; 59,61; e 46,41\%, respectivamente, para o capim-elefante e os fenos de alfafa e capim coast-cross. A utilização destes valores na equação 25, para a predição da energia digestível dos alimentos supracitados, resulta em valores de 1,79; 2,22; e 1,86 Mcal ED/kg MS, respectivamente, para o capim-elefante e os fenos de alfafa e capim coastcross, próximos aos obtidos por ALMEIDA et al. (1999), ainda que, para o feno de capim coast-cross, o conteúdo de ED tenha sido subestimado em 10,5\%.

MARTIN-ROSSET (1990) propõe o uso de equações de predição do coeficiente de digestibilidade aparente da matéria orgânica, em função do teor de
FB (g/kg MS), sendo a equação para o feno de leguminosas descrita como CDMO $(\%)=90,52-$ $0,0995 \mathrm{FB}\left(\mathrm{r}^{2}=66,6 \%\right)$, enquanto para o feno de gramíneas é descrita como CDMO $(\%)=87,89-$ $0,1180 \mathrm{FB}\left(\mathrm{r}^{2}=71,1 \%\right)$. A utilização destas equações de predição do CDMO e da equação 25 , para a predição do conteúdo de ED dos alimentos supracitados, resulta em estimativas de 2,35 e 1,77 Mcal ED/kg MS, respectivamente, para o feno de alfafa e capim coast-cross, demonstrando que a predição do conteúdo de energia digestível do feno de alfafa foi adequada, porém o conteúdo de ED do feno de capim coast-cross foi subestimado em 14,7\%. Resultados semelhantes foram obtidos utilizando a equação 25 e a equação de predição do CDMO, em função do teor de FB, em alimentos volumosos, proposta por SMOLDERS et al. (1990), equação descrita como CDMO $(\%)=111,8-0,178 \mathrm{FB}\left(\mathrm{R}^{2}=80,3 \%\right)$ que estima o conteúdo de energia digestível em 1,79; 2,22; e 1,86 Mcal ED/kg MS, respectivamente, para o capim-elefante e os fenos de alfafa e capim coastcross, mostrando-se adequada para a predição do conteúdo de ED do feno de alfafa, porém subestima, respectivamente, em 9,7 e 11,9\% o conteúdo de ED do capim-elefante e feno de capim coast-cross.

A equação 35 do presente trabalho mostrou-se eficiente para a estimativa do conteúdo de proteína digestível do feno de alfafa, semelhante ao observado com as equações propostas por FONNESBECK (1969) e MARTIN-ROSSET et al. (1984), porém superestimou o conteúdo de PD do capim-elefante e subestimou o conteúdo de PD do feno de capim coast-cross. Da mesma forma, as equações para a estimativa da PD em dietas para eqüinos citadas na literatura mostraram-se inadequadas para o capimelefante e feno de capim coast-cross.

\section{Conclusões}

Os teores de fibra bruta, fibra em detergente neutro, fibra em detergente ácido, celulose e lignina nas dietas estão negativamente relacionados com o conteúdo de energia e proteína digestível, enquanto o coeficiente de digestibilidade aparente da matéria orgânica está positivamente correlacionado à energia digestível das dietas. O teor de hemiceluloses não se apresentou como bom preditor da energia ou proteína digestível das dietas.

As melhores equações de predição da energia digestível foram obtidas em função dos teores de MO, FDA e do coeficiente de digestibilidade da matéria orgânica nas dietas. Em dietas exclusiva- 
mente com alimentos volumosos e em dietas mistas com alimentos volumosos e concentrados, a energia digestível pode ser predita adequadamente em função do coeficiente de digestibilidade da matéria orgânica. A predição do coeficiente de digestibilidade da proteína bruta em alimentos volumosos pode ser obtida em função de seu conteúdo de proteína bruta.

\section{Referências Bibliográficas}

ALMEIDA, M.I.V. Predição da energia digestível de dietas para eqüinos a partir de seu conteúdo fibroso. Belo Horizonte, MG: UFMG, 1994, 104p. Dissertação (Mestrado em Zootecnia) - Universidade Federal de Minas Gerais, 1994.

ALMEIDA, M.I.V., FERREIRA, W.M., ALMEIDA, F.Q. et al. 1999. Valor Nutritivo do capim-elefante (Penninsetum purpureun, Schum), do feno de alfafa (Medicago sativa, L.) e do feno de capim coast-cross (Cynodon dactylon (L.) Pers.) para eqüinos. Rev. bras. zootec., 28(4):743-752.

DACCORD, R., VUIGNIER, R. 1991. Evaluation de la qualité des aliments composés pour chevaux. Rev. Suisse Agric., 23(3):151-154.

FONNESBECK, P.V. 1981. Estimating digestible energy and TDN for horses with chemical analysis of feeds. J. Anim. Sci., 53:241 (Abstract). (Suppl. 1)

FONNESBECK, P.V. 1969. Partitioning the nutrients of forages for horses. J. Anim. Sci.,28(3):624-633.

HINTZ, H.F., REUTER, M.J., SIROIS, P. 1992. Effect of fiber content on digestible energy content of oats. Eq. Practice, 14(4):5-7.

MARTIN-ROSSET, W. 1990. Lälimentation des chevaux. Paris: INRA. 232p.

MARTIN-ROSSET, W., ANDRIEU, J., VERMOREL, M et al. 1984. Valeur nutritive des aliments pour le cheval. In: Le Cheval. Reproduction, sélection, alimentation, exploitation.
Paris: INRA. p.209-238.

MELO, I.M.P. 1990. Prediction of digestibility of feedstuffs using cell wall constituents and enzimatic solubilities. World Rev. Anim. Prod., 25(1):83-88.

MINSON, D.J. 1982. Effect of chemical composition on feed digestibility and metabolizable energy. Nutr. Abstr. Rev., Series B, 52:591-615.

NATIONAL RESEARCH COUNCIL - NRC. 1989. Nutrient requirements of horses. 5 ed. Washington: National Academy of Science. 100p.

OLSSON, N., RUUDVERE, A. 1955. The nutrition of the horse. Nut. Abst. Rev., 25(1):1-18.

ROBINSON, D.W., SLADE, L.M. 1974. The current status of knowledge on the nutrition of equines. J. Anim. Sci., 39(6):1045-1065.

SMOLDERS, E.A.A., STEG, A., HINDLE, V.A. 1990. Organic matter digestibility in horses and its prediciton. Netherlands J. Agric. Sci., 38(5):435-447.

STATISTICAL ANALYSIS SYSTEM - SAS. 1990 - SAS/STAT User's Guide (Release 6.03). SAS - Inst. Inc., Cary, N.C. $485 \mathrm{p}$.

VANDER NOOT, G.W.V., TROUT, J.R. 1971. Prediction of digestible components of forages by equines. J. Anim. Sci., 33(1):38-41.

WEISS, W.P. 1993. Predicting energy values of feeds. J. Dairy Sci., 76(6):1802-1811.

WEISS, W.P. 1998. Estimating the available energy content of feeds for dairy cattle. J. Dairy Sci., 81(3):830-839.

WOLTER, R. 1975. Alimentación del caballo. Zaragoza: Ed. Acribia.172p.

Recebido em: 02/07/98

Aceito em: 19/05/99 